\title{
Vitamin P - Do Certain Polyphenolic IMPS Have a Vital Function?
}

David S. Seigler, ${ }^{1}$ J. Brent Friesen, ${ }^{2,3,4,5}$ Jonathan Bisson, ${ }^{2,3,4}$ James G. Graham, ${ }^{2,3,4}$ Ana Bedran-Russo, ${ }^{3,6}$ James B. McAlpine, ${ }^{2,3,4}$ and Guido F. Pauli $2,3,4$

${ }^{1}$ Department of Plant Biology, University of Illinois at Urbana Champaign, Urbana Champaign, IL, USA; ${ }^{2}$ Center for Natural Products Technologies, ${ }^{3}$ Program for Collaborative Research in Pharmaceutical Sciences (PCRPS), and ${ }^{4}$ Department of Pharmaceutical Sciences, College of Pharmacy, University of Illinois at Chicago, Chicago, IL , USA; ${ }^{5}$ Physical Sciences Department, Dominican University, River Forest, IL, USA; ${ }^{6}$ Department of Restorative Dentistry, College of Dentistry, University of Illinois at Chicago, Chicago, IL, USA 
Author disclosures: No conflict of interest.

Address correspondence to GFP (e-mail: gfp@uic.edu).

Abbreviations used: IMPS, invalid/improbable/interfering metabolic panaceas; PAC, proanthocyanidins; OPAC, oligomeric proanthocyanidins.

Number of Figures: 1

Number of Tables: 0

Running Title: Vitamin P - Are Polyphenolic IMPS Vital Nutrients?

Word count: $~ 7,100$ 


\section{Abstract}

In the 1930s, it was discovered that the ability of synthetic Vitamin C to treat scurvy was inferior to plant extracts containing Vitamin C. This observation led to the proposal of Vitamin P (permeability), as an essential phytochemical dietary nutrient. Subsequent attempts to isolate and characterize Vitamin P led to confusing and sometimes irreproducible results. Over the years several flavonoids and coumarins have been identified as having Vitamin P-like activity. Essentially all of these Vitamin $P$ candidates were recently identified as IMPs (Invalid/Improbable/Interfering Metabolic Panaceas) in a NAPRALERT meta analysis. While the

historic inability to define a single compound and specific mode of action led to general skepticism about the Vitamin P proposition, the more logical conclusion is that several abundant and metabolically labile plant constituents fill this essential role in human nutrition. This review of $100+$ years of multilingual Vitamin $\mathrm{P}$ and $\mathrm{C}$ literature provides the rationales for this conclusion.

Keywords: Vitamin P, Vitamin C, flavonoids, plant phenylpropanoids, capillary resistance 


\section{Introduction}

\section{Motivation and Goal of the Study}

Building on more than a century of primary literature published in English, French, and German, the present study compiles existing evidence and presents an intriguing perspective for the connection between the existence of Vitamin P as a known, but difficult to identify, cofactor of vital body functions in humans, and flavonoid dietary plant constituents that have been designated as invalid/improbable/interfering metabolic panaceas (IMPS) (1).

This study was motivated by the recent proof of the existence of IMPS as over studied natural products that have an implausible plethora of reported biological activities, making them panaceas, in theory, but lacking the essential characteristics of drug leads such as well-defined structureactivity relationships, stability, and other general parameters of drugability. Following the premise that unrecognized life-essential biological functions of molecules may potentially blur their experimentally observable in vivo and in vitro effects, the study sought to unravel the link between flavonoids and Vitamin P. Flavonoids are nearly ubiquitous in plants, and likely represent the most well-studied class of plant constituents. Therefore, they comprise the largest group in the top-38 known IMPS (1).

The following study develops a set of rationales for the ability of flavonoids and some phenylpropanoids, structurally and biogenetically closely related plant phenols, to possess biological functions that are essential for healthy human life. These functions involve peripheral collagenous, vascular tissue and, include the permeability of vascular capillaries and cerebral tissue, and therefore have a significant impact on cardiovascular and general human health. The surprisingly elusive nature and lack of an assigned single chemical entity of these, otherwise essential, bioactive molecules can be rationalized by the dietary omnipresence and metabolic interconversion of the flavonoid species that have been experimentally associated with both Vitamin P and Vitamin C bioactivities.

\section{Improbable as Drug Leads, Invalid as Panaceas, Interfering as Screening Agents - but Valid as a Vitamin and Essential Food Ingredient?}

Recently, a systematic meta-analysis of world literature on bioactive natural products, encoded in NAPRALERT (2), led to the discovery that certain plant-based metabolites (often considered as 
"secondary metabolites") have received massive but essentially non-productive attention in the literature. Termed as invalid metabolic panaceas (IMPS), these compounds show bioactivity in virtually all known biological endpoints, frequently due to bioassay "interference", but they fail to succeed in their development as drugs ("improbable leads") or other effective intervention agents. The inability to develop IMPS into drugs, despite major research efforts, is reflected in their alternative designation as improbable leads, established in parallel to them being invalid panaceas. Collectively, IMPS as improbable drug leads can undermine natural products drug discovery (1).

However, these findings do not preclude important biological functions for these compounds. In fact, highly abundant molecules may play crucial roles in biological systems - even if their roles are "passive" (i.e., not involving a definable active site, receptor, or analogous target) and not druglike, but rather function as essential components. While located at the "extreme end" of such a concept, water could still serve as an example. Focusing on phenolic compounds that belong to the group of flavonoids (Supporting Information S1), the possible existence of un(der)recognized vital biological functions is illustrated in studies of Vitamin P, which was first co-discovered with Vitamin C in the 1930s by Szent-Györgyi. In order to understand the relationship of flavonoid IMPS and Vitamin P, it is necessary to place the discovery of vitamins and, in particular, Vitamin $\mathrm{C}$ into perspective.

\section{Brief History of Vitamins}

Early in the $20^{\text {th }}$ century, the research of several investigators indicated that a family of organic substances found in foods were essential for human life. One of these early investigators, Funk, recognized that small amounts of these substances were essential, and that their absence was responsible for many common diseases such as beriberi, pellagra, and scurvy (3-5). Funk termed these substances vitamines, or "vital amines", based on the original discovery of thiamin, an amine found to be involved in beriberi. In 1920, Drummond (6) proposed that the term be shortened to "vitamin" as non-amine essential compounds were discovered. He further proposed that thiamine and riboflavin be called Vitamins A and B, respectively, to contrast them from Funk's anti-scurvy factor, which he called Vitamin C (7).

Although modern definitions differ somewhat, an essential organic chemical compound (or set

of related compounds) is called a vitamin when it cannot be synthesized by the organism at all or in sufficient quantities and, therefore, must be obtained through diet. Thus, the term vitamin is 
conditional upon the circumstances and particular organism. For example, ascorbic acid (Vitamin $\mathrm{C}, \mathbf{1})$ is a vitamin for humans and guinea pigs, but not for rats and most other animals (8). The well-known Vitamins A, C, D, E, K, and Vitamins of the B complex were among those subsequently discovered in the early part of the twentieth century and later accepted as vitamins (9). In contrast, the proposed Vitamin P was almost forgotten. Putting Vitamin P into proper perspective requires a review of Vitamin $\mathrm{C}$ discovery and basic physiology.

\section{Vitamin C}

\section{Vitamin C and Scurvy}

By the mid-1700s, scurvy debilitated and killed those whose diet was largely based on meat and starch and devoid of fresh vegetables and fruits. Although the problem was widespread, this was especially difficult for the British navy, as numerous British sailors were afflicted with this disease $(9,10)$. Attempting to ameliorate this situation, a Scottish physician, James Lind, had observed the curative and preventive powers of citrus fruits and wrote an essay (1757) recommending mandatory consumption of citrus fruits and lemon juice by sailors in the British Navy, eventually leading to their colloquial designation as "limeys". However, it would take a century for scientists to understand why citrus fruits were so effective against scurvy $(9,10)$.

Commonly recognized symptoms of scurvy are loss of weight; swollen, soft, spongy or ulcerated gums; loose carious teeth; hemorrhages; necrosis of the bones, swollen joints; edema; hardening of the skin and often perifollicular or petechial hemorrhages, sometimes bloody conjunctiva and occasionally anemia (11). In the absence of Vitamin C, the development and maintenance of intercellular substances degrades. This involves the collagen of all fibrous tissues and of all non-epithelial cement substances, such as intracellular material of the capillary wall, cartilage, dentin, and bone matrices (11). It has been the prevailing view that scurvy and the deficiency states of Vitamin $\mathrm{C}$ are marked by unduly fragile capillaries, despite a considerable body of evidence that there is no direct association of capillary strength and Vitamin $\mathrm{C}$ in humans nor in guinea pigs (see (12) and citations therein).

In 1907, two Norwegians, Holst and Fröhlich, reported the existence of a substance that, based on observed biological effects, had the ability to cure the symptoms of scurvy (13). Further, they were able to demonstrate that the absence of this substance produced the symptoms of scurvy in 
guinea pigs, which are unable to synthesize the substance endogenously. This work was largely ignored because, at that time it was generally accepted that only lipids, proteins, and carbohydrates were needed for growth and development of animals.

In approximately 1924, the Hungarian scientist Szent-Györgyi began to study animal, vegetable, and synthetic oxidizing systems (14). By 1928, he had isolated and accumulated about 30 grams of a strongly reducing substance, which he called hexuronic acid, from adrenal tissue, citrus species, and cabbage. Further, Szent-Györgyi also provided a sample of hexuronic acid to Haworth, an eminent chemist who, in turn, passed the sample to colleagues who determined the structure (15). Interestingly, in his early studies, Szent-Györgyi did not carry out bioassays to establish that his substance was the antiscorbutic compound, but provided a sample to another investigator, Zilva, who, in 1932, declared that Szent-Györgyi's hexuronic acid was not Vitamin C (16-19).

Perhaps slightly after Szent-Györgyi had begun his studies on hexuronic acid in 1928, King at Pittsburgh began complementary studies. King's contribution involved the isolation of Vitamin C from lemon juice in 1931-1932 and study of its antiscorbutic activity in guinea pigs (20,21). The research groups of King and Szent-Györgyi connected when a Hungarian-American, Svirbely, worked with King at the University of Pittsburgh until 1931, returned to Hungary and worked with Szent-Györgyi. By early 1932, Svirbely had established that hexuronic acid was the antiscorbutic factor identical to Vitamin C (1) (15,22-24). Within two weeks of each other in the spring of 1932, first Waugh and King $(25,26)$, and then Svirbely and Szent-Györgyi (15) published articles declaring that Vitamin $\mathrm{C}$ and hexuronic acid were the same compound, thus $\mathbf{1}$ was subsequently named ascorbic acid $(27,28)$. Later work by Szent-Györgyi and his collaborators, with the diet of Sherman et al. (29) for induction of scurvy in guinea pigs, was the first to demonstrate Vitamin C avitaminosis $(15,23)$ and finally explained its link with the treatment and prevention of scurvy (10).

Szent-Györgyi was awarded a Nobel Prize in Medicine in 1937 for his work with regard to $\mathbf{1}$ However, controversy remains over whether both Szent-Györgyi and King deserved equal credit for the discovery of $\mathbf{1}$. Szent-Györgyi's further accomplishments included the discovery of the role of adenosine triphosphate and actin-myosin, elucidation of many phases of the Krebs cycle, and 
studies on the influence of free radicals in tumor formation $(30,31)$. Haworth received the 1937 Nobel Prize in Chemistry for his investigations on the chemistry of carbohydrates and $\mathbf{1 .}$

\section{Vitamin P Emerged from Vitamin C Research}

Many biochemical processes involve $\mathbf{1}$ and its oxidized counterpart, dehydroascorbate (1b), as cofactors: hydroxylase metabolism; (nor)adrenalin biosynthesis in the adrenal cortex; formation of dopamine (2a) and norepinephrine (2b; syn. noradrenalin) in adrenergic synapses; and metabolism of aromatic amino acids (Supporting Information S5). The most characterized function of 1 involves collagen biosynthesis, where it takes part in the post-translational hydroxylation of prolyl and lysyl residues in unfolded procollagen chains, which is essential for folding collagen into triple helices prior to fibroblast secretion. Hydroxyproline residues contribute to the stiffness of the collagen triple helix, and hydroxylysine residues hydrogen bond with carbohydrates and form intramolecular cross-links that give structural integrity to the collagen mass. The underhydroxylation of procollagen, which is degraded, appears to be a major factor in the pathophysiology of scurvy. Vitamin $\mathrm{C}$ deficient subjects usually show reduced urinary excretion of hydroxyproline (32).

From the collagen pathophysiology perspective, the Vitamin $\mathrm{C}$ story is quite satisfying. An avitaminosis condition could be treated by a single biologically active compound, designated as Vitamin C, and chemically identified as ascorbic acid (1). Structure activity relationships have been established (Supporting Information S2) and specific biological targets identified. However, the Vitamin P story emerges from the Vitamin C narrative. Although Szent-Györgyi was awarded the Nobel Prize for the discovery of Vitamin C, according to some, he was never fully satisfied, because his experiments with Vitamin C showed something was "missing" $(21,28)$. This is where Vitamin $\mathrm{P}$ enters the picture.

Early Vitamin C studies were performed with natural product extracts, which contained 1 along with other compounds (impurities) that accounted for the residual complexity (minor chemical species in nature-derived agents that impact biological test systems and bioactivity profiles of the assay material (33)). Vitamin $\mathrm{C}$ became the focus of these studies as it was the major component of the extracts. Moreover, the role of putative impurities was obscured by the apparent success of 1 to reverse most, but not all, biological effects of a scorbutic diet in guinea pigs and humans. 


\section{Vitamin P}

\section{Early Evidence for Vitamin P as a Flavonoid}

Although the structure of Vitamin C was still unknown in the 1920s, several investigators at the time provided evidence that Vitamin $\mathrm{C}$ interacted with a second factor of unknown composition (34-37). Based on these reports and his own experiments, with isolated and characterized Vitamin C, Szent-Györgyi also believed that there was an additional chemical factor that played a significant role in curing scurvy $(21,28)$. He felt that this additional substance was of similar importance and related activity with Vitamin C. In the dietary absence of both Vitamin $\mathrm{C}$ and this

unknown entity, the symptoms of scurvy prevailed and concealed symptoms of the deficiency of the second substance (38). Along with other investigators, he found that in certain pathological conditions characterized by an increased permeability or fragility of the capillary wall, highly purified or synthetic 1 was ineffective for reducing the permeability, whereas the condition was readily cured by administration of extracts of Hungarian red pepper (called "Vitapric") or lemon juice. These extracts were effective in cases of decreased resistance of the capillary wall toward whole blood (vascular type of hemorrhagic purpura), as well as in cases where the capillary wall showed increased permeability toward plasma protein only, such as observed in various septic conditions. As little as $40 \mathrm{mg}$ of this active fraction given daily intravenously to a human restored normal capillary resistance in two weeks. Spontaneous bleeding ceased, the capillary walls lost their fragility towards pressure differences, and no more plasma protein left the vascular system on increased venous pressure (38).

In a second publication, Szent-Györgyi and co-workers demonstrated that when guinea pigs were fed a diet that induced scurvy, those that also received $1 \mathrm{mg}$ daily of the crystalline flavonoid fraction of lemon juice (called citrin) survived much longer than those that did not. Those animals not receiving this extract died in 28 days, whereas those with citrin lived 44 days on average. Both groups showed typical symptoms of scurvy, but the group that only received Vitamin $\mathrm{C}$ had major increases in hemorrhages of several types in comparison to groups that received both Vitamin $\mathrm{C}$ $(2 \mathrm{mg})$ and citrin $(39,40)$. The authors argued that these results indicated that experimental scurvy, as it is commonly known, is a deficiency disease caused by the combined lack of $\mathbf{1}$ and other components of the lemon extract. Accordingly, they proposed the name "Vitamin P" for the substance responsible for the action on (vascular) permeability. The decision to call this material 
a "vitamin" later proved to be a source of controversy (30). Zacho investigated the impact of citrin (see the Supporting Information for a comprehensive description of citrin) in capillary resistance in guinea-pigs ( $\mathrm{n}=36)$ fed with various diets using the sucking-cup method adopted from the human clinical use to the animal model (41). His findings confirmed that citrin was effective in restoring normal capillary resistance from scorbutogenic dietary conditions.

Unfortunately, several workers, notably Zilva $(18,42)$, were not able to duplicate the effects of citrin and its interactions with Vitamin C as claimed by Szent-Györgyi and coworkers (43-45). Even Szent-Györgyi was not always able to duplicate his own results $(46,47)$. However, in other cases, the initial observations of activity of citrin and other flavonoid fractions could be repeated (12). Although the difficulty to repeat the original work may have been for a variety of reasons, one major problem was that the preparations used by Szent-Györgyi and coworkers were not consistent in composition $(45,46,48-50)$. From today's perspective, these reported reproducibility issues could be interpreted as a form of (chemical) residual complexity. Researchers attempted to isolate the active component of citrin. Upon fractionation, the active fraction from lemon juice was found to consist primarily of flavonoid glycoside(s). The experimental description of the production of citrin, the phytochemical methods available at the time, and the incomplete compound purification (without crystallization to constant m.p.) most likely yielded materials with variable chemical composition.

Despite the fact that Armentano et al. (51) found that use of lemon juice and preparations of paprika rich in Vitamin C produced favorable results in certain patients with bleeding diseases, namely vascular purpura and protein permeability of the capillaries, the same results were not observed with purified Vitamin C. From these studies, it appeared that purified and synthetic Vitamin $\mathrm{C}$ were less effective than unpurified Vitamin $\mathrm{C}$ from natural sources for treating thrombocytopenic purpura. These observations reinforced the notion that bioactive minor compounds, attributed to residual complexity, were present in the Vitamin C-rich extracts. Lavollay demonstrated that injection of pure, synthetic Vitamin C caused elevation of capillary resistance in non-scorbutic guinea pigs ( $2 \mathrm{mg}$ per $400 \mathrm{~g}$ animal), whereas injection of the flavanone, epicatechin (3a; $1 \mu \mathrm{g}$ ), was 10,000 to 20,000 times more effective than $\mathbf{1}$. Others also have not detected any increase in capillary resistance following administration of $\mathbf{1}$ alone to apparently healthy persons on inadequate diets or to persons with scurvy $(44,51-53)$. Interestingly, a very recent meta analysis of 17 qualifying clinical trials has associated the flavonoid quercetin 
with lowered systolic blood pressure as a clinical endpoint, in the absence of lipid and glucose metabolic effects (39).

Even today, residual complexity plagues programs aimed at natural product drug discovery. The ambiguities in the reported interaction of flavonoid preparations such as citrin and $\mathbf{1}$ foreshadows the ongoing difficulties that have been experienced with performing biological assays on nature-derived materials. The intricacies of purity and the chemical integrity of assay materials has recently been recognized as a persistent problem in biological assays (54).

\section{Expanding the Repertoire of Vitamin P Candidates}

With the Vitamin P hypothesis in hand, a search was undertaken to identify a chemical principle that enhanced the activity of Vitamin $\mathrm{C}$ for treating the cause and symptoms of scurvy. A major problem in the search for a specific compound that could be identified as Vitamin P proved to be that a series of structurally diverse flavonoids from other sources also produced similar results. For example, the glucoside of the flavonoids hesperidin (4a) and desmethoxyhesperetin (4b) were both active. In comparison, the flavonoids fractions of Citrus extracts contained heterosides of quercetin (5a). In some cases, comparative activities were measured, for example, citrus fruit concentrates were reported to have 20 times the activity of hesperidin $(50,53)$. In his publications, SzentGyörgyi concluded that Vitamin P should be a flavanone with exceptional properties owing to its activity vis-à-vis oxidative agents (46). However, Javillier and Lavollay noted that the activity was not associated with specific flavonoid structures, but also with many flavonoids including flavonols, flavanones, and their glycosides, as well as catechins and their oligomeric proanthocyanidins (Figure 1) (49).

Catechins from cutch (Senegalia catechu [syn. Acacia catechu], catechu) proved to be a source of Vitamin P-like activity. Although Lavollay et al. found the original crystalline (+)-catechin (6) from cutch to be inactive $(55,56)$, the mother liquor was quite active. Notably, (-)-epicatechin (3a), from the mother liquors was 500 to 1,000 times more active than the flavonoid fraction from citrus extracts (55-57). This example of "dynamic" residual complexity (54) plausibly had resulted from an epimerization event that occurred during recrystallization of a compound isolated by bioassay guided fractionation. Based on LC/MS and LC/MS/MS analyses, it is now known that the major

monomeric catechins of cutch are (+)-catechin (6), (-)-epicatechin (3a), epicatechin-3-O-gallate (7a), and epigallocatechin-3-O-gallate (7b) (58). Extracts of gambier, Uncaria gambir 
(Rubiaceae), a source of the catechin oligomers called proanthocyanidins, were also found to be active. Gambier extracts contain primarily $(+)$-catechin (6) and only small amounts of (-)epicatechin (3a) (59).<smiles>O=C1O[C@H]([C@H](O)CO)C(O)=C1O</smiles><smiles>O=C1OC([C@@H](O)CO)C(=O)C1=O</smiles><smiles>[R2]NCC([R])c1ccc(O)c(O)c1</smiles>
2a $\mathrm{R}_{1}=\mathrm{R}_{2}=\mathrm{H}$ dopamine 2b R $\mathrm{R}_{1}=\mathrm{OH} \mathrm{R} \mathrm{R}_{2}=\mathrm{H}$ norepinephrine 2c $\mathrm{R}_{1}=\mathrm{OH} \mathrm{R} \mathrm{R}_{2}=\mathrm{Me}$ epinephrine<smiles>[R]c1cc([C@H]2Oc3cc(O)cc(O)c3C[C@H]2O)cc(O)c1O</smiles>

3a $\mathrm{R}=\mathrm{H}(-)$-epicatechin 3b R=OH (-)-epiegallopicatechin<smiles>Oc1cc(O)c2c(c1)O[C@H](c1ccc(O)c(O)c1)C(O)C2</smiles><smiles>COc1cc(O)cc(O)c1C(=O)CCc1ccc(O)cc1</smiles><smiles>Oc1ccccc1O</smiles>

10 catechol<smiles>Oc1cccc(O)c1O</smiles>

11 pyrogallol<smiles>[R]Oc1ccc([C@H]2CC(=O)c3c(O)cc(O)cc3O2)cc1O</smiles>

4a $\mathrm{R}=\mathrm{Me}$ hersperitin 4b $\mathrm{R}=\mathrm{H}$ eriodyctiol<smiles>O=C(O[C@H]1Cc2c(O)cc(O)cc2O[C@@H]1c1cc(O)c(O)c(O)c1)c1cc(O)c(O)c(O)c1</smiles><smiles>O=c1c(O)c(-c2ccc(O)c(O)c2)oc2cc(O)cc(O)c12</smiles>

5a $\Delta_{2,3} \quad$ quercetin 5b 2,3-diH taxifolin<smiles>[R20]c1cc2ccc(=O)oc2cc1O</smiles>

8a $\mathrm{R}=\mathrm{H}$ esculetin 8b $R=\beta$-D-glc esculin

7a $\mathrm{R}=\mathrm{H}$ epicatechin-3-O-gallate 7b $\mathrm{R}=\mathrm{OH}$ epicatechin-3-O-gallate<smiles>Oc1cc(O)c2c(c1)O[C@H](c1ccc(O)c(O)c1)C(c1c(O)cc(O)c3c1O[C@H](c1ccc(O)c(O)c1)[C@H](O)C3)[C@H]2O</smiles>

12 leucocyanidol

15 proanthocyanidin B1

FIGURE 1. Structures of the natural products featured in the Vitamin P story: vitamin C (syn. ascorbic acid; 1); dopamine (2a), norepinephrine (noradrenaline; $\mathbf{2 b}$ ) and epinephrine (adrenaline; $\mathbf{2 c}$ ); (-)-epicatechin (5a) and (-)-epigallocatechin (5b); hersperitin (4a) and eriodyctiol (4b); quercetin (5a) and taxifolin (5b); (+)-catechin (6), (-)-epicatechin-3-O-gallate (7a) and (-)-epigallocatechin-3-O-gallate (EGCG; 7b); esculetin (8a) and esculin (8b); phlorizin (9); catechol (10) and pyrogallol (11); leucocyanidin (12) and proanthocyanidin B1 [epicatechin- $(4 \beta \rightarrow 8)$-catechin] (13). 
In subsequent studies, the French investigators found that coumarin and the coumarin derivatives esculin (8a) and esculetin (8b) also were quite active (60). A flavonoid dihydrochalcone, phlorizin (9), even showed activity in microgram quantities (49). Coumarins are widespread in nature, however, 9 is best known as an apple skin component and is only occasionally found in other plants.

In 1948, Masquelier founded a company that prepared an extract of the bark from French maritime pine, Pinus pinaster Aiton subsp. atlantica Villar, called $\underline{\text { Pycnogenol }}{ }^{\circledR}$, that had Vitamin C-like properties (Supporting Information S4) (61). Chemical identification studies showed that this extract is primarily composed of proanthocyanidins that are biopolymers of $\mathbf{6}$ and $\mathbf{5 a}$ with 2 or more flavonoid subunits. The extract also contained monomeric $\mathbf{6}$ and the $\mathbf{5 b}$.

Lavollay and Sevestre demonstrated that Bordeaux wine, from which the alcohol was removed, possessed Vitamin P activity when injected into guinea pigs and humans (62). Masquelier and coworkers later discovered the presence of oligomeric proanthocyanidins in red wines $(63,64)$. About 1970, it was discovered that grape seeds were also rich in oligomeric proanthocyanidins. Early research on the effects of grape seed extracts on the permeability of vascular capillaries was designed to unravel the underlying cellular and molecular mechanisms of action of oligomeric proanthocyanidins and other flavonoids (65).

During the 1970's, Masquelier began producing a grape seed extract for medicinal uses as an alternative to the pine-derived Pycnogenol ${ }^{\circledR}$. Grape seeds contain a similar, but not identical complement of the oligomeric proanthocyanidins (OPCs; syn OPACs) to pine bark. Masquelier's product, called “MASQUELIER's ${ }^{\circledR}$ Original OPCs", was extracted from the seeds of Vitis vinifera L. This product contained catechins, epicatechins, and $\mathrm{OP}(\mathrm{A}) \mathrm{Cs}$ (dimers to pentamers) (66). Detailed analyses have established that the product is standardized to contain about $85 \%(\mathrm{w} / \mathrm{w})$ flavonoids, of which 50-60\% (w/w) are monomeric and dimeric catechins. The same product was evidently devoid of OP(A)Cs $(65,67)$.

In vitro studies indicate that Pycnogenol ${ }^{\circledR}$ constituents demonstrate a high percentage of binding to collagen fibers, promote synthesis of collagen and elastin, and inhibit their proteolytic degradation (68). Masquelier's OP(A)Cs have been demonstrated to bind collagen and elastin in blood vessel walls, promote collagen synthesis and polymerization, and inhibit degradation of collagen and elastin in a study conducted in guinea pigs (69). The OP(A)Cs of grape seed show 
strong collagen protection. By binding to collagen, they also may offer protection of elastin and collagen in vascular tissues from degradation by elastase and collagenase respectively (65).

Flavonoids such as (-)-epicatechin and dimeric procyanidins in human diets can be absorbed and reach the bloodstream and other organs $(67,70,71)$. O(A)PCs consisting of larger numbers of monomeric units are poorly absorbed and mostly pass through the digestive system unaltered. In this process, a portion of certain $\mathrm{OP}(\mathrm{A}) \mathrm{Cs}$ bind to membranes of the gastrointestinal tract. These substances have a key role in stabilizing membranes by preventing their disruption via chemical and biological agents, and regulating membrane-associated events. In many instances, OP(A)Cs appear not to bind directly to degradative enzymes, but to bind to matrix macromolecules and prevent their degradation by various factors such as temperature, oxidative stress, inflammation, and proteinases (67,70-74). The original lemon and paprika extracts studied by Szent-Györgyi and others are rich in $\mathbf{1}$ and a variety of flavanones, but essentially lack catechins and proanthocyanidins (75-77).

Fibrillar collagen is a strong and viscoelastic biomaterial arranged into highly organized hierarchical structures. Type 1 collagen is the most abundant of all collagen types and is defined as an interwoven coiled trimer, containing repeated sequences of proline and hydroxyproline (78). The interaction of OP(A)Cs and collagen is believed to be stabilized by hydrogen bonding between the protein amide carbonyl and hydrophobic bonds. The relatively great stability of OP(A)Cprotein complexes suggests structural specificity. Indeed, two new trimeric and tetrameric A-type $\mathrm{OP}(\mathrm{A}) \mathrm{Cs}$ capable of strengthening the micromolecular backbone of teeth via intermolecular and intermicrofibrillar cross-linking have been reported (79). The applications in dentistry include disease prevention (caries) and partial tooth repair.

In conclusion, while astute experimental observations concerning the residual complexity of early Vitamin C preparations from natural sources led to the Vitamin P hypothesis, the residual complexity of Vitamin P formulations (also prepared from natural extracts) led to considerable confusion in identifying a "lead compound" in the search for Vitamin P. It has not been possible to attribute Vitamin P activity to a specific food, preparation, or compound. This problem, coupled with the difficulty in attributing a deficiency disease that could clearly be linked to SzentGyörgyi's lemon extracts or to Vitamin P might have led scientists to abandon Vitamin P as a useful hypothesis. Nonetheless, despite the difficulties in understanding the relation of Vitamins 
$\mathrm{C}$ and P, two things have been established: (i) the existence of a distinct biological effect of Vitamin P, i.e., the influence of a series of naturally occurring flavonoids and coumarins (Figure 1 and Figure S1, Supporting Information) on vascular permeability; and (ii) the influence of these natural products on the anti-scurvy effect of Vitamin C $(44,48,65)$.

\section{Evidence for Vitamin P Avitaminosis}

One of the early objections to consideration of Vitamin P as a true vitamin lay in the difficulty of establishing disease symptoms that were related to the identified series of compounds. This shortcoming was addressed by later studies of Casley-Smith and coworkers who worked mostly with rats, which have the ability to synthesize Vitamin C endogenously. When fed a diet lacking flavonoids, the rats exhibited definite structural alterations in blood capillaries and tissues. A diet of this type, for the time period employed, produced considerable increases in capillary fragility. These fine structural alterations were quite different from those reported for Vitamin $\mathrm{C}$ avitaminosis and implied a different deficiency $(80,81)$. Other work demonstrated that lack of flavonoids gives rise to cerebral edema due to the increased permeability of the blood-brain barrier (82). In skin, a flavonoid-deficient diet greatly increased capillary fragility, which was reversed by the addition of flavonoids to the diet (80).

Medicinal preparations involving a semisynthetic flavonoid compound, $O$-( $\beta$-hydroxyethyl)rutoside, were developed about 1960 (83). The corresponding drug, Venoruton ${ }^{\circledR}$, has been widely used in Germany and Switzerland for the treatment of edema and other vascular disorders. Oral administration of Venoruton ${ }^{\circledR}$ increased conjunctival capillary resistance in rabbits. This drug has few negative side effects and, importantly, is soluble in water, whereas rutin and other flavonoids with similar activity have limited water solubility.

Studies with guinea pigs and humans implied that natural flavonoids and coumarins acted as vitamins in those animals, and that Vitamin C (1) and Vitamin P deficiency states are quite distinct. The structural effects of Vitamin C deficiency in both guinea pigs and humans have been studied by a number of workers who noted a significant reduction in the amount of collagen, with swelling of the fibroblasts and endoplasmic reticulum. The basement membranes of the blood capillaries (and associated lymphatics) were often very tenuous and disrupted, although they sometimes appeared thicker (80). In contrast, in Vitamin P avitaminosis in rats, the basic lesion consisted of the opening of some blood capillary endothelial intercellular junctions. Unlike in Vitamin C 
avitaminosis, the endothelial cells were intact, without a pale, grossly swollen cytoplasm (80). These effects were largely prevented by feeding coumarins as well as flavonoids such as troxerutin $(80,83,84)$.

The studies by Casley-Smith implied that the natural flavonoids and coumarins were vitamins. Vitamin C (1) and Vitamin P deficiency states are sufficiently distinct to justify the assignment of Vitamin $\mathrm{P}$ as the underlying factor. It seems probable that some of the changes in Vitamin $\mathrm{C}$ deficiency observed in many studies were due to a concomitant Vitamin P deficiency. Whereas both conditions had many open endothelial junctions and somewhat altered basement membranes, all the gross distortions of the endothelial cells observed in Vitamin $\mathrm{P}$ avitaminosis were considerably lessened by flavonoids and coumarins.

\section{Early Ideas on the Mechanism of Action of Vitamin P}

Probably because adrenal glands were an original source of Vitamin C, and due to the fact that adrenalin (2c) was a major factor in capillary blood flow, much attention was focused on adrenalin as a link to Vitamin $\mathrm{P}$ activity $(48,62,85)$. In vitro experiments showed that $\mathbf{2 c}$ is readily oxidized by catechol oxidase, the cytochrome system, amine oxidases, and peroxidases (86). Javillier and Lavollay supposed that Vitamin P slowed down oxidation and thereby the resulting inactivation of 2c (49,87-89); 2c can also be inactivated by non-oxidative enzymes, such as catechol-Omethyltransferase. The ability of many different types of flavonoids and coumarins to affect the persistence of $\mathbf{2 c}$ was evaluated in a subsequent extensive study (85).

It is likely $2 \mathbf{c}$ is involved in the action of Vitamin P: it binds to $\alpha-1$ receptors that are involved with vasoconstriction, smooth muscle contraction of the bladder neck, and glycogenesis. Adrenalin also binds to $\alpha-2$ receptors, which are involved with vein constriction, central attenuation of the sympathetic nervous system, inhibition of insulin release, and relaxation of the intestine. Other interactions include $\beta-1$ receptors that provide positive inotropic and positive chronotropic signals to the heart, lipolysis, renin release, as well as $\beta-2$ receptors, providing bronchodilation, vasodilation, gluconeogenesis, relaxation of the uterus, and relaxation of the intestine. The ubiquitin receptor (vascular dopamine [2a]) DA1 is involved with vasodilation, whereas the DA2 receptor prevents presynaptic noradrenaline release (http://www.urologytextbook.com/adrenal-glands-catecholamins.html; (90)). The plasma half-life of 2c is 
approximately $20 \mathrm{~s}$. Inactivation depends mainly on monoamine oxidase (MAO) and catecholamine- $O$-methyltransferase (COMT) availability.

Early experiments with flavonoids examined their role in the metabolism of 2c. Injection of quercitroside inhibited decomposition of $\mathbf{2 c}$ in dogs and cats. In addition, 2c extended the physiological action of adrenaline in cats (45). In guinea pigs that were scorbutic, a number of other substances were shown to inhibit oxidation of adrenaline in vitro, however, most of them, e.g., catechol (11) and pyrogallol (12), were not substances that would normally be found in the diet or in animals $(56,57)$.

Alternatively, other investigators concluded that the activity of Vitamin $\mathrm{P}$ consisted of inhibiting the oxidation of 1. In 1947, Masquelier isolated a flavan-3,4-diol, leucocyanidol (13), from the seed coats of peanuts (91-93). He found that extracts containing flavan-3,4-diols could protect Vitamin $\mathrm{C}$ from oxidation in vitro. He also demonstrated that rutin, esculin $(\mathbf{8 b})$, and $\mathbf{1 3}$ all inhibited in vitro oxidation of Vitamin $\mathrm{C}$ mediated by $\mathrm{Cu}^{2+}$ ions and ascorbic acid oxidase. In subsequent work, Masquelier referred to "leucocyanidol" as "OPCs" (oligomeric proanthocyanidins) although in his 1951 papers, he refers to the tested substance as the monomer, 13 (91-93). Later, Bate-Smith and Ribéreau-Gayon confirmed that the original "leucocyanidol" isolated was indeed a flavan-3,4-diol (94). Overall, Masquelier examined the health benefits of probable mixtures of these compounds and, based on his subsequent studies, developed a vasculoprotective medicine in 1950. However, the (somewhat surprising) limited availability of peanut skins necessitated examination of other plants sources of active antioxidant substances (28).

At first sight, the role of Vitamin P as an "antioxidant" in biological systems might appear an attractive explanation for many aspects of the biological role of flavonoids, because it can easily be rationalized why so many diverse flavonoids and related phenylpropanoids display Vitamin Pactivity. However, "antioxidant" bioactivity does not adequately explain the apparent link between Vitamin C and Vitamin P activity, especially as Vitamin C could, presumably, act as its own antioxidant. Polyphenolic flavonoid compounds such as flavan-3-ols, flavan-3,4-diols, and oligomeric proanthocyanidins (including procyanidin B1 [15]) have radical scavenging activity and, therefore, have been proposed to serve as "antioxidants". It is now known that vascular function is strongly influenced by oxidative stress and that diminishing oxidative stress also reduces inflammatory stress (65). However, flavonoids and related compounds, as well as extracts 
containing these compounds, may be involved in a multitude of biological functions and may have multiple (pleiotropic) effects that during evolution have not been selected for a strong effect on a single well-defined target $(65,67)$, but rather the opposite.

\section{Plausibility of Flavonoids as Bioactive Compounds}

The NAPRALERT Database (2) was consulted to investigate the plausibility of flavonoids as bioactive compounds. Plant natural products from 421 families, 3,714 genera, and 16,011 species are represented in NAPRALERT. A much smaller number of plants have been examined for biological activity. A NAPRALERT search revealed that approximately 50,000 biological experiments have been published on flavonoids. About half of these are based on commercially available materials. The other half included flavonoids from about 1,700 species of living organisms, primarily plants. Almost 7,000 compound names associated with these experiments are represented. The qualitative activity, i.e., overall active to inactive activity, reported for these compounds is $2: 1$ (3:1 in vivo) which means that $66-75 \%$ of flavonoids have been reported as being bioactive in their respective assays.

Flavonoids also have been reported to have bioactivity in a very broad variety of bioassays. They undoubtedly interact with many different systems in mammals. These pleiotropic interactions may be detrimental or beneficial. Note that flavonoids and related phenolics often interfere with bioassays and, therefore, are described as pan-assay interference compounds (PAINS) (95). PAINS interfere with in vitro assays through various mechanisms including fluorescence, redox, or through generalized binding to enzymes. As a result, flavonoids represent 10 of the 22 natural products that have been identified as most likely being natural product invalid metabolic panaceas (IMPS) (1).

\section{Final Observations on the Vitamin P Hypotheses}

\section{Are Vitamin C and Vitamin P Mutual Co-factors?}

One early experimental approach to explore this question used guinea pigs, which like humans, lack the ability to synthesize Vitamin $\mathrm{C}$. They were divided into five groups. A control group was given Vitamin C, whereas other groups received no or sub-optimal levels of Vitamin C, but were given various levels of OP(A)Cs. Even though deprived of Vitamin C, those that received an appropriate amount of $\mathrm{OP}(\mathrm{A}) \mathrm{Cs}$ survived as long as those that got adequate amounts of Vitamin 
C. Lotze concluded that Vitamin $\mathrm{C}$ and $\mathrm{OP}(\mathrm{A}) \mathrm{Cs}$ have a marked synergy because coadministration of OP(A)Cs and Vitamin $\mathrm{C}$ made it possible to decrease the dosage of Vitamin $\mathrm{C}$ $(21,44,52,96)$. Pleiotropic effects (multiple biological effects from the same phytoconstituent) may also explain bioactivity that cannot be rationalized by classical reductionist models (67).

\section{Does the Metabolic Transformation of Flavonoids Contribute to Their Bioactivity?}

When considering bioactivity research that is dominated by live animal assays, it is necessary to consider the contribution of the dynamic complexity of metabolites to the observed activity. Unfortunately, the stability and metabolism of catechins and other flavonoids under digestive conditions is poorly understood. However, several common food additives including Vitamin C, milk, and citrus juice enhance the stability of epicatechin (5a), epigallocatechin (5b), epigallocatechin gallate (7), and epicatechin gallate (6), when incorporated into tea beverages. From in vitro digestion studies, without additives, less than $10 \%$ of epigallocatechin gallate (7) and epicatechin gallate (6) were recovered. Addition of Vitamin C (1) increased recovery to 54 and $74 \%$, respectively, while epicatechin (5a) recovery was $82 \%$. Of all substances tested, juice preparations promoted stability best. Epicatechin recovery was then between 86 and $95 \%$. Of the juices tested, lemon juice was most effective. Catechins are most stable in aqueous solutions at about pH $4(97,98)$.

Vitamins C and P may play a joint role in the biological activity of Vitamin C $(99,100)$. Vitamin $C$ reacts with $p$-hydroxybenzyl alcohol to produce two epimeric forms of 1, 2-C-(parahydroxybenzyl-3-keto-hexulosonic acid (99). These authors also indicated that $\mathbf{1}$ can react with leucoanthocyanidins (flavan-3,4-diols) and proanthocyanidins (such as 13) to produce adducts. Both 3 and 6 contain a similar structural moiety and can react similarly (100). Metabol(om)ic relationships including xenobiotic conversions, which exist between the flavonoid structures and structurally distinct derivatives and/or reactive species may be the actual carriers of the Vitamin P effect.

\section{Do Modern Interpretations Shed Light on Historical Reports?}

Unambiguous data show that the activity of Vitamins $\mathrm{C}$ and $\mathrm{P}$ are related. In a number of studies, guinea pigs on a scorbutogenic diet developed symptoms of scurvy and the animals also developed reduced capillary resistance. This latter effect was reversed by addition of citrin, hesperidin, or 
other flavonoids to the diet. Interpretation of data from different methods for determination of capillary resistance and lack of experimental details contributed to variation in the results of many of the studies reviewed by Scarborough and Bacharach (48).

Other problems result from the composition of scorbutic diets used to study the role of Vitamin $\mathrm{C}$ and Vitamin $\mathrm{P}$ in guinea pigs and rats. Many early studies, including those of both King and Szent-Györgyi, were based on a scorbutic diet that consisted mainly of freshly ground oats (Avena sativa), dried milk powder, salt, and butter fat. Notably, oats contain (-)-epicatechin, a compound with pronounced Vitamin P-like activity (101). The presence or absence of (-)-epicatechin and related flavanols in the diets employed, opens questions about the interpretation of the results of many of these early studies.

Nonetheless, we concur that Vitamin P activity is real. At the same time, the strict definition of a vitamin as a single chemical entity (SCE), the absence of which generates a disease (avitaminosis), does not apply because of the complex composition and interrelated nature of the compounds that can serve as Vitamin P. In this respect, Vitamin P resembles a complex similar to Vitamin B. While the definition of Vitamins P1, P2 , P3 etc. is premature, they differ from the B-series by being structurally related.

Much of the vast reported evidence suffers from being chemically inconclusive, due to a lack of rigor in the chemical characterization of the intervention materials. While this in part reflects the progress in chemical and structural analysis made since performing the biological assays that characterized the vitamins, other potential explanations for the gap in our current understanding of Vitamin P may lie in the following shortcomings: (a) a general trend towards bioassays that are driven by reductionist hypotheses (single agent, single target) vs. consideration of pleiotropic activity/targets (multiple biological effects originating from the same phytoconstituent); (b) the general lack of consideration of metabolic activation, in particular the conversion of polyphenols with poor PK properties into metabolites that can be absorbed; (c) a tendency to ignore all forms of residual complexity, particularly the impurity of the natural products used in bioassays (static $\mathrm{RC}$ ), as well as stability/conversion during bioassay and/or chemical processing (e.g., heating during recrystallization, triggering epimerization and other chemical reactions). 


\section{Does Vitamin P Exist as a Single Chemical Entity?}

Considering the evidence available to date, Vitamin P does not exist as a single chemical entity, but consists of a group of analogous and often congeneric compounds. As mentioned above, a number of flavonoids and flavonoid glycosides have been considered to be "Vitamin P". However, these compounds mostly have limited activity in comparison to certain coumarins (Figure 2), as well as the flavonoids phloridzin (9) and epicatechin (5a). Epicatechin (5a) and oligomeric flavonoids (such as procyanidin B1, 15) are widely distributed among plants, and are found in many food plants.

Whether 5a and/or OP(A)Cs constitute a vitamin (complex), related or unrelated to Vitamin $\mathrm{C}$, is, in part, a question of definitions. Notably, it has not been demonstrated unambiguously that Vitamin $\mathrm{C}$ alone is adequate for resolving the symptoms of scurvy (53). In the opinion of Masquelier, flavan-3-ol oligomers (i.e.,. catechol oligomers or oligomeric proanthocyanidins $[\mathrm{OP}(\mathrm{A}) \mathrm{Cs}]$ ) are the only flavonoids that have a justified claim to vitaminic activity (21). Further, there is significant evidence that coumarin derivatives, which share a biogenetic and ADMET relationship with flavonoids, have Vitamin $\mathrm{P}$ activity and also interact in a powerful manner with Vitamin C $(44,52)$.

Although Vitamin P has not been widely accepted by the scientific community, numerous commercial dietary supplements are currently sold as "Vitamin P". The variety of chemical structures associated with commercial products sold with the label "Vitamin P" is as diverse as all the structures shown in this article, with the exception of the coumarins.

\section{Are Flavonoids a Group of Metabolically Interchangeable Essential Nutrients with Poorly Understood Biological Profiles?}

The historic and ubiquitous nature of flavonoids in the human diet suggests that they may have become essential dietary nutrients at some point in the evolution of the human species. In fact, it is difficult to devise a diet that is completely deficient in these compounds. Moreover, the highly generic nature of flavonoids as bioactive compounds suggests that no single compound emerged as playing a decisive role. This seems to indicate that a more generalized activity might be at work, which is strikingly well aligned with the Screening Hypothesis by Firn and Jones $(102,103)$. This does not rule out the possibility of specific biological targets, which remain to be determined. In 
fact, there may be many specific biological targets that are impacted by chemical members of the Vitamin P family $(65,67)$.

The difficulty in discerning a specific biological Vitamin $\mathrm{P}$ activity for a specific compound is a direct result of the behavior of many polyphenolic compounds in bioactivity assays that makes them "Invalid Metabolic Panaceas" (IMPs). Nevertheless, this apparent dilemma can also be understood as an opportunity and justification for future experiments that seek to connect a network of multiple phytochemicals with the multitude of biological effects that collectively constitute the Vitamin P activity.

\section{Acknowledgements}

The authors gratefully acknowledge funding through NCCIH/NIH grant U41 AT008706 (Center for Natural Products Technologies).

\section{Notes \& Dedication}

In 1960, my [DSS] personal interest in this topic originated in the seminar class of Dr. Charles Schwartz of Southwestern Oklahoma State University, Weatherford, OK, in which I wrote an assigned report on vitamins. Obviously, that report and the attendant presentation were much too broad for a single 50-minute seminar, but provided an early introduction to the Vitamin P literature.

\section{References}

1. Bisson J, McAlpine JB, Friesen JB, Chen S-N, Graham J, Pauli GF. Can Invalid Bioactives Undermine Natural Product-Based Drug Discovery? J Med Chem. 2016;59:1671-90.

2. NAtural PRoducts ALERT Database, University of Illinois at Chicago, Chicago (IL); napralert.org.

3. Die Vitamine, ihre Bedeutung für Physiologie und Pathologie mit Besonderer Berücksichtigung der Avitaminosen: (Beriberi, Skorbut, Pellagra, Rachitis) Anhang: Die Wachstumsubstanz und das Krebsproblem. JAMA. 1914. p. 1042.

4. Funk CK. The etiology of the deficiency diseases. Beriberi, polyneuritis in birds, epidemic dropsy, scurvy, experimental scurvy in animals, infantile scurvy, shop beriberi, pellagra. Journal of State Medicine. 1912;20:341-68.

5. Spedding S. Vitamins are more Funky than Casimir thought. Australas Med J. 2013;6:104-6.

6. Jack Drummond - Wikipedia. Wikimedia Foundation (https://en.wikipedia.org/wiki/Jack_Drummond). 
7. Drummond JC. The Nomenclature of the so-called Accessory Food Factors (Vitamins). Biochem J. 1920;14:660.

8. Vitamin C - Wikipedia. Wikimedia Foundation (en.wikipedia.org/wiki/Vitamin_C).

9. McDowell L. Vitamin History, the Early Years. First Edition Design Pub.; 2013. 290 p.

10. Chemheritage Profile of Albert Szent-Györgyi; www.chemheritage.org/historical-profile/albertszent-györgyi [cited 2020 Mar 12].

11. Charles O. Wilson, Ole Gisvold, J. B. Textbook of organic medicinal and pharmaceutical chemistry. 3rd ed. Lippincott Co., Philadelphia; 1956.

12. Scarborough H. CLXXII. Vitamin P. Biochemical Journal. 1939. p. 1400-7.

13. Holst A, Frölich T. Experimental Studies Relating to Ship-beri-beri and Scurvy. II. On the Etiology of Scurvy. Epidemiology and Infection. 1907. p. 634-71.

14. Szent-Györgyi A. Observations on the function of peroxidase systems and the chemistry of the adrenal cortex. Biochemical Journal. 1928. p. 1387-409.

15. Svirbely JL, Szent-Györgyi A. Hexuronic Acid as the Antiscorbutic Factor. Nature. 1932. p. 576576.

16. Zilva SS. The Antiscorbutic Fraction of Lemon Juice. II. Biochemical Journal. 1924. p. 632-7.

17. Zilva SS. The Antiscorbutic Fraction of Lemon Juice. V. Biochemical Journal. 1927. p. 689-97.

18. Zilva SS. Hexuronic Acid as the Antiscorbutic Factor. Nature. 1932. p. 690-690.

19. Zilva SS. A Note on the Precipitation of the Antiscorbutic Factor from Lemon Juice. Biochemical Journal. 1927. p. 354-5.

20. Svirbely JL, King CG, Others. The preparation of vitamin C concentrates from lemon juice. Journal of Biological Chemistry. 1931;94:483-90.

21. Schwitters B, Masquelier J. OPC in practice: Biflavanals and their application. Alfa Omega, Rome, Italy. 1993.

22. Hirst EL, Reynolds RJW. Hexuronic Acid as the Antiscorbutic Factor. Nature. 1932. p. 576-7.

23. Svirbely JL, Szent-Györgyi A. The chemical nature of vitamin C. Biochem J. 1932;26:865-70.

24. Hoffer A. The discovery of Vitamin C. J Orthomol Med. 1989;4:24-6.

25. Waugh WA, King CG. Isolation and identification of vitamin C. J Biol Chem. American Society for Biochemistry and Molecular Biology; 1932;97:325-31.

26. King CG, Waugh WA. The Chemical Nature of Vitamin C. Science. 1932;75:357-8.

27. Szent-Györgyi A, Haworth WN. "Hexuronic Acid" (Ascorbic Acid) as the Antiscorbutic Factor. Nature. 1933. p. 24-24. 
28. Spounias J. The Mysterious "Vitamin P.” The American Free Press. June 21, 2015

29. Sherman HC, LaMer VK, Campbell HL. The Quantitative Determination of the Antiscorbutic Vitamin (Vitamin C). Journal of the American Chemical Society. 1922. p. 165-72.

30. Grzybowski A, Pietrzak K. Albert Szent-Györgyi (1893-1986): The scientist who discovered vitamin C. Clinics in Dermatology. 2013. p. 327-31.

31. Moss RW. Free radical: Albert Szent-Gyorgyi and the battle over vitamin C. Paragon House Publishers; 1988. 316 p.

32. Combs GF, Jr. The Vitamins. Academic Press; 2012. 598 p.

33. Publication Series: Residual Complexity of Bioactive Natural Products (go.uic.edu/residualcomplexity).

34. Randoin L. Constitution de deux régimes définis pour l'étude du scorbut et de la polynéurite aviare. Bull Soc Sci Hyg Aliment Aliment Ration Homme. 1923;11:453-67.

35. Scotti-Foglieni. Sulle vitamine. Boll Soc Ital Biol Sper. 1926;1:159-60.

36. Bezssonoff MN. L'effet antiscorbutique est-il dû à deux substances différentes? Bulletin de la Société Chimique Biologique. 1927;568-79.

37. Bezssonoff MN. L'effet antiscorbutique est-il dû à deux substances différentes? C R Hebd Acad Sci. 1926;183:1309-10.

38. Rusznyák ST, Szent-Györgyi A. Vitamin P: Flavonols as Vitamins. Nature. 1936. p. 27-27.

39. Huang H, Liao D, Dong Y, Pu R. Effect of quercetin supplementation on plasma lipid profiles, blood pressure, and glucose levels: a systematic review and meta-analysis. Nutr Rev. 2020;

40. Bentsáth A, Rusznyák ST, Szent-Györgyi A. Vitamin Nature of Flavones. Nature. 1936;137:906.

41. Zacho CE. The Influence of Ascorbic Acid and of Citron on the Capillary Resistance of GuineaPigs. Acta Pathol Microbiol Scand. Wiley Online Library; 1939;16:144-55.

42. Zilva SS. Vitamin P. Biochem J. 1937;31:915-19.

43. Moll T. Zur Frage des Vitamin P. Klin Wochenschr. 1937;16:1653-1653.

44. Lotze H. Kritisches über das „Vitamin P”. DMW - Dtsch Med Wochenschr. 1938;64:477-80.

45. Parrot J, J. Sevestre. Sur la nature de la vitamin P. L'epicatéchine, substance jusqu'ici la plus active sure la résistance capillaire. Comptes rendus hebdomadaires des séances d l'Academie des Sciences. 1943;540-2.

46. Szent-Györgyi A. Methoden zur Herstellung von citrin. Hoppe Seylers Z Physiol Chem.1938;255:126-31

47. Benthsáth A, Rusznyák ST, Szent-Györgyi A. Vitamin P. Nature. 1937;139:326-7.

48. Scarborough H, Bacharach AL. Vitamin P in Vitamins and Hormones. New York: Academic Press, 
Inc; 1949.

49. Javillier M, Lavollay J. Les substances agissant sur la résistance et la perméabilité capillaires et la notion de vitamine P. Health Care Anal. 1946;29:1283-9.

50. Higby RH, Others. Chemical nature of hesperidin and its use as source of vitamin P. J Am Pharm Assoc. 1941;30:629-35.

51. Armentano L, Bentsáth A, Béres T, Rusznyák S, Szent-Györgyi A. Über den Einfluß von Substanzen der Flavongruppe auf die Permeabilität der Kapillaren. Vitamin P1. Dtsch Med Wochenschr.1936;62:1325-8.

52. Lotze H. Untersuchungen über das „Vitamin P“. Zeitschrift für Die Gesamte Experimentelle Medizin.1938;102:697-727.

53. Scarborough H, Bacharach AL. Vitamin P. Vitamins \& Hormones.1949;7:1-55.

54. Simmler C, Hajirahimkhan A, Lankin DC, Bolton JL, Jones T, Soejarto DD, Chen S-N, Pauli GF. Dynamic residual complexity of the isoliquiritigenin-liquiritigenin interconversion during bioassay. J Agric Food Chem. 2013;61:2146-57.

55. Lavollay, J., J. Parrot, and J. Sevestre. Sur la nature de la vitamine P. L'épicatéchine, substance jusqu'ici la plus active sur la résistance capillaire. 1943;217:540-2.

56. Lavollay J. L'action de l'acide ascorbique sur la résistance capillaire du cobaye normal. Comparaison avec celle des vitamins P. C R Seances Soc Biol Fil. 1944;138:816-7.

57. Lavollay J. La function vitaminique P. Elévation de la résistance capillaire du cobaye par les inhibiteurs classiques de l'oxydation de l'adrénaline. C R Seances Soc Biol Fil. 1944;138:803-10.

58. Shen D, Wu Q, Wang M, Yang Y, Lavoie EJ, Simon JE. Determination of the predominant catechins in Acacia catechu by liquid chromatography/electrospray ionization-mass spectrometry. J Agric Food Chem. 2006;54:3219-24.

59. Duangyod T, Palanuvej C, Ruangrungsi N. commercial black catechu and pale catechu. J Chem Pharm Res.;2014;6:2225-32.

60. Silvestre J, Lavollay J. Sur la nature de la vitamin P. Remarquable activité de l'esculoside sur la résistance capillaire. C R Hebdomad Séances Acad Sci. 1944;218:979-80.

61. Oliff HS, Blumenthal. M. Scientific and Clinical Monograph for PYCNOGENOL $®$. American Botanical Council; 2010.

62. Lavollay J, Sevestre J. Le vin considére comme un aliment riche en vitamin P. Comptes rendus hebdomadaires des séances de l'Academie d'Agriculture de France. 1944;30:259-61.

63. Masquelier J, Vitte G, Ortega M. Dosage colorimétrique des leucoanthocyannes dans vins rouges. Bull Soc Pharm Bord. 1959;98:145-8.

64. Masquelier J, Jensen. H. Recherches sur l'action vitaminique P du vin. Bull. Soc. Pharm. Bordeaux. 1955;94:80-94.

65. Weseler AR, Bast A. Masquelier's grape seed extract: from basic flavonoid research to a well- 
characterized food supplement with health benefits. Nutr J. 2017.

66. Gabetta B, Fuzzati N, Griffini A, Lolla E, Pace R, Ruffilli T, Peterlongo F. Characterization of proanthocyanidins from grape seeds. Fitoterapia. 2000;71:162-75.

67. Weseler AR, Ruijters EJB, Drittij-Reijnders M-J, Reesink KD, Haenen GRMM, Bast A. Pleiotropic benefit of monomeric and oligomeric flavanols on vascular health--a randomized controlled clinical pilot study. PLoS One. 2011;6:e28460.

68. Tixier JM, Godeau G, Robert AM, Hornebeck W. Evidence by in vivo and in vitro studies that binding of pycnogenols to elastin affects its rate of degradation by elastases. Biochem Pharmacol. 1984;33:3933-9.

69. Pfister A, Simon MT, Gazave JM. Sites de fixation des oligomeres procyanidoliques dans la paroi des capillaires sanguins du poumon decobaye. Acta Ther. 1982;223-37.

70. Verstraeten SV, Fraga CG, Oteiza PI. Interactions of flavan-3-ols and procyanidins with membranes: mechanisms and the physiological relevance. Food Funct. 2015;6:32-41.

71. Walle T. Absorption and metabolism of flavonoids. Free Radic Biol Med.; 2004;36:829-37.

72. Laparra J, Michaud J, Masquelier J. Etude pharmacocinetique des oligomeres flavanoliques. Plantes Med Phyto. 1977;11:133-42.

73. Hollman PCH. Absorption, Bioavailability, and Metabolism of Flavonoids. Pharm Biol. 2004;42:74-83.

74. Chen Z, Zheng S, Li L, Jiang H. Metabolism of flavonoids in human: a comprehensive review. Curr Drug Metab. 2014;15:48-61.

75. Nogata Y, Sakamoto K, Shiratsuchi H, Ishii T, Yano M, Ohta H. Flavonoid composition of fruit tissues of Citrus species. Biosci Biotechnol Biochem. 2006;70:178-92.

76. Peterson JJ, Beecher GR, Bhagwat SA, Dwyer JT, Gebhardt SE, Haytowitz DB, Holden JM. Flavanones in grapefruit, lemons, and limes: A compilation and review of the data from the analytical literature. J Food Compost Anal. Elsevier; 2006;19:S74-80.

77. Bhagwat S, Haytowitz D, Prior R, Others. USDA Database for the Proanthocyanidin Content of Selected Foods, Release 2. US Department of Agriculture, Agricultural Service, Nutrient Data Laboratory: Beltsville, MD, USA. 2015.

78. Bedran-Russo AK, Pauli GF, Chen S-N, McAlpine J, Castellan CS, Phansalkar RS, Aguiar TR, Vidal CMP, Napotilano JG, Nam J-W, et al. Dentin biomodification: strategies, renewable resources and clinical applications. Dent Mater. 2014;30:62-76.

79. Nam J-W, Phansalkar RS, Lankin DC, McAlpine JB, Leme-Kraus AA, Vidal CMP, Gan L-S, Bedran-Russo A, Chen S-N, Pauli GF. Absolute Configuration of Native Oligomeric Proanthocyanidins with Dentin Biomodification Potency. J Org Chem. 2017;82:1316-29.

80. Casley-Smith JR, Földi-Börcsök E, Földi M. A fine structural demonstration that some benzopyrones act as vitamin P in the rat. Am J Clin Nutr. 1975;28:1242-54.

81. Gábor M. Pharmacologic Effects of Flavonoids on Blood Vessels. J Vasc Res. 1972;9:355-74. 
82. Vákonyi T, Wittmann T, Varró V. Effect of local circulatory arrest on the structure of the enterocytes of the isolated intestinal loop. Digestion. 1977;15:295-302.

83. Voelter W, Jung G. O-( $\beta$-Hydroxyethyl)-rutoside: Neue Ergebnisse in Experiment und Klinik. Springer-Verlag; 2013. 288 p.

84. Schäfer-Korting M, Marshall M, Loew D. Chemisch definierte Ödemprotektiva. Venenerkrankungen. 2003. p. 149-207.

85. Clark WG, Geissman TA, Others. Potentiation of effects of epinephrine by flavonoid ("vitamin P"like) compounds. Relation of structure to activity. J Pharmacol Exp Ther. 1949;95:363-81.

86. Richter D. The inactivation of adrenaline in vivo in man. J Physiol. 1940;98:361-74.

87. Bain WA, Batty JE. Inactivation of adrenaline and noradrenaline by human and other mammalian liver in vitro. Br J Pharmacol Chemother. 1956;11:52-7.

88. Lavollay J, Neumann J. ctivation du système d'oxydation peroxydasique de l'adrénaline par des substances polyphénoliques naturelles dérivées de la flavone (phenyl-benzo- $\gamma$-pyrone). C R Hebdomad Séances Acad Sci. 1941;212:193-5.

89. Lavollay J, Neumann. J. La function vitaminique P. Action chimique, pharmacodynamique et physiologique de substances naturelles inhibant l'autoxydation de l'adrénaline. C R Hebdomad Séances Acad Sci. 1941;212:251-251.

90. Benninghoff A. Makroskopische Anatomie, Embryologie und Histologie des Menschen. München, Wien, Baltimore: Urban \& Schwarzenberg. 1993;

91. Tayeau F, Masquelier J. Etude Chinique sur les pigments de la fraine darachide. 1. Le chromogene. Bull Soc Chim Fr. 1948;15:1167-72.

92. Masquelier J. Comparative action of different vitamin P substances on the oxidation of ascorbic acid by copper ions. Bull Soc Chim Biol. 1951;33:302-3.

93. Masquelier J. Action comparée de divers facteurs vitaminiques P sur l'acide ascorbique-oxydase. Bull Soc Chim Biol. 1951;33:304-5.

94. Bate-Smith EC, Ribéreau-Gayon P. Leuco-anthocyanins in seeds. Qualitas Plantarum et Materiae Vegetabiles. 1959;5:189-98.

95. Baell JB, Holloway GA. New substructure filters for removal of pan assay interference compounds (PAINS) from screening libraries and for their exclusion in bioassays. J Med Chem. 2010;53:271940.

96. Laparra J, Michaud J, Masquelier J. Action des oligomeres procyanidoliques sur le cobaye carence en vitamine c. Tavaux Originaux, University of Bordeaux. 1976;

97. Green RJ, Murphy AS, Schulz B, Watkins BA, Ferruzzi MG. Common tea formulations modulate in vitro digestive recovery of green tea catechins. Mol Nutr Food Res. 2007;51:1152-62.

98. Li N, Taylor LS, Ferruzzi MG, Mauer LJ. Kinetic study of catechin stability: effects of pH, concentration, and temperature. J Agric Food Chem. 2012;60:12531-9. 
99. Kiss G, Neukom H. Bildung eines ascorbigenähnlichen Produktes aus p-Hydroxybenzylalkohol und L-Ascorbinsäure. Experientia. 1968;24:326-326.

100. Michaud J, Masquelier J. Quelces Aspectes nouveaux de la connoissance des tannins ctaecholiques. Leurs relations avec la vitamine C2 (P). Prod Prob Pharm. 1973;28:499-520.

101. Khang DT, Vasiljevic T, Xuan TD. Bioactive compounds, antioxidant and enzyme activities in germination of oats (Avena sativa L.). Food Chem Toxicol. 2016;23.

102. Firn RD, Jones CG. Natural products - a simple model to explain chemical diversity. Nat Prod Rep. 2003;20:382-91.

103. On the evolution of plant secondary chemical diversity. Philos Trans R Soc Lond B Biol Sci. 1991;333:273-80.

104. Seigler DS. Plant Secondary Metabolism. 2012. 759 p.

105. Reichstein T, Schwarz L, Grüssner A. Zur Kenntnis des Vitamnis C. Synthese der 6-Methyl-1arabo-3-keto-hexonsäure-lactons (1-Rhamno-ascorbinsäure). Helv Chim Acta. 1935;18:353-4.

106. Reichstein T, Grüssner A, Oppenauer R. Synthese der d-und l-Ascorbinsäure (C-Vitamin). Helv Chim Acta. 1933;16:1019-33.

107. Rohdewald P. Pleiotropic Effects of French Maritime Pine Bark Extract to Promote Healthy Aging. Rejuvenation Res. 2019;22:210-7.

108. Rohdewald P. A review of the French maritime pine bark extract (Pycnogenol), a herbal medication with a diverse clinical pharmacology. Int J Clin Pharmacol Ther. 2002;40:158-68.

109. Raal A, Nisuma K, Meos A. Pinus sylvestris L. and other conifers as natural sources of ascorbic acid. Journal of Pharmacy \& Pharmacognosy Research. Asociación de Académicos de Ciencias Farmacéuticas de Antofagasta; 2018;6:89-95.

110. Schoonees A, Visser J, Musekiwa A, Volmink J. Pycnogenol ${ }^{\circledR}$ for the treatment of chronic disorders. Cochrane Database Syst Rev. 2012;CD008294.

111. Hughes CD, Swenson MJ, Underbjerg GKL, Hughes JS. The Function of Vitamin C in the Adrenal Cortex. Science. 1952;116:252-3. 